\title{
SER OU NÃO SER JAPONÊS? UM PROCESSO IDENTITÁRIO EM CONSTRUÇÃO
}

\author{
Adriana Capuano de Oliveira ${ }^{1}$ \\ Danielle Yura ${ }^{2}$
}

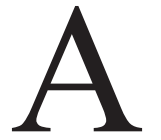

imigração japonesa para o Brasil foi, ao longo do século $\mathrm{XX}$, uma das mais controvertidas e interessantes correntes migratórias que o país recebeu, graças a uma série de condições peculiares ao seu desenvolvimento. $\mathrm{O}$ artigo que ora apresentamos traz uma proposta de análise desse percurso migratório de forma abrangente, trabalhando desde seus precedentes históricos até o momento contemporâneo, no qual os desdobramentos dessa imigração suscitam novas e surpreendentes reflexões, como o reverso dessa trajetória, hoje, de brasileiros que emigram para o Japão. $\mathrm{O}$ estudo primordial de todo esse contexto migratório pauta-se na questão do sentimento de partilhar uma identidade nacional comum. Através da história dessa migração, podemos investigar como o sentimento de se vincular a uma identidade nacional transforma-se devido ao deslocamento per se, por um lado, e em decorrência das atribuições que a sociedade receptora designa a esses imigrantes, por outro lado, alterando subjetivamente a noção de ser ou não ser um nacional de determinado país, no caso aqui analisado, de ser ou não japonês e ser ou não brasileiro.

1 Docente da Universidade Federal do ABC (UFABC). Doutora em Ciências Sociais pela Universidade Estadual de Campinas (Unicamp). capuano.oliveira@gmail.com.

2 Mestre em Ciências Humanas e Sociais pela UFABC. Jornalista da Assessoria de Comunicação da Reitoria do Instituto Federal de Educação, Ciência e Tecnologia de São Paulo (IFSP). danielleyura@gmail.com. 
O sentimento de pertencer a uma coletividade que nos distingue dos demais (nossos diferentes) acompanha a humanidade desde seus primórdios. Contudo, a percepção de pertencer a uma coletividade vinculada a um estado-nação fortaleceu-se sobremaneira nos séculos XVIII e XIX, quando esse modelo de organização política ganhou força, especialmente nas sociedades ocidentais. Brasil, como uma coletividade que só poderia entender-se como estado-nação a partir do século XIX (antes disso, colônia portuguesa), e Japão, que só partilharia dessa necessidade igualmente no século XIX (antes disso, xogunato), trilharão caminhos intercruzados a partir da história de seus imigrantes. De acordo com o conceito de comunidade imaginada, apontado por Stuart Hall, uma cultura nacional é fundamentada em um discurso que constrói identidades a partir da produção de sentidos sobre uma nação, com os quais podemos nos identificar. ${ }^{3}$ Essas identificações, contudo, não são rígidas nem inflexíveis, ao contrário, possuem uma dinamicidade que se multiplica quando vinculada a processos migratórios, como no caso da população em análise.

Dessa forma, o contexto que precede a concretização da imigração japonesa no Brasil mostra-se relevante, sobretudo porque, a partir dele, uma série de situações e circunstâncias levará a possíveis conceituações de identidade. Assim, o artigo desenvolve-se com base nesse contexto histórico precedente no item "O contexto da imigração japonesa para o Brasil”, que conduzirá o leitor a uma melhor compreensão dos momentos subsequentes, em que a imigração em si já se efetiva e produz as condições necessárias para um processo de isolamento, censura e discriminação desse grupo ("A imigração japonesa até a Guerra: percepções de identidade").

$\mathrm{O}$ item "O perigo amarelo e os anos que antecederam a Guerra: a Assembleia Constituinte de 1933 e a Lei de Cotas de 1934" versa sobre um período importante para a compreensão dos processos identitários dos imigrantes japoneses no Brasil, qual seja, o momento que antecede a Segunda Guerra Mundial. Anos antes da eclosão da guerra, o governo ditatorial de Getúlio Vargas convocou a Assembleia Constituinte de 
1933, cujas implicações sobre os processos imigratórios no Brasil foram contundentes. A condução do cerceamento das liberdades aumentou no decorrer dos anos subsequentes e, com a entrada do Brasil na Segunda Guerra, de acordo com as posturas divergentes adotadas pelos dois países (Brasil e Japão), os imigrantes japoneses aqui residentes passaram por um período de privações e dificuldades exacerbadas. Este texto busca destacar justamente como a repressão e censura desencadeada sobre esse grupo causou percepções de identidade descontextualizadas da realidade, provocando a ocorrência de acirramentos e posições intransigentes, a ponto de fortalecer associações ultranacionalistas, como a Shindo Renmei. Esse é o contexto primordial do item "Os duros anos da Guerra: repressão, censura e isolamento", que colocará em perspectiva as análises de pertencimento a uma identidade nacional.

O item "Redefinindo a identidade: não há mais retorno possível!" versa sobre as mudanças decorrentes do desfecho da Segunda Guerra Mundial e suas consequências, mais uma vez analisando e enfatizando as percepções identitárias. Com o final da guerra, acabaram também as ilusões de pertencer a uma sociedade que não existe mais. Por fim, o último item, "E hoje?", coloca em perspectiva o desenvolvimento da comunidade japonesa no Brasil até os dias atuais, quando o processo emigratório se instala entre os descendentes dos imigrantes japoneses. Nesse cenário, novas apreensões identitárias são possíveis graças ao fluxo "inverso" propiciado pela emigração de brasileiros (filhos, netos e bisnetos desses imigrantes japoneses) para o Japão, seguido ainda de um novo panorama das migrações internacionais, agora dentro de uma dinâmica muito mais acelerada e frenética, relacionada aos processos de globalização do sistema internacional.

As análises apresentadas são resultado de pesquisas realizadas pelas autoras em momentos diferentes desse contexto migratório e com foco em grupos diferentes de imigrantes relacionados ao processo de deslocamento Japão-Brasil e Brasil-Japão. Enquanto uma pesquisou, entre os anos de 1995 a 1997, o movimento dekassegui com constantes atualizações até o momento, a outra debruçou-se, entre os anos de 2014 a 2016, sobre a história da imigração japonesa no Brasil, sobretudo no período da Segunda Guerra Mundial. Para a execução dessas pesquisas, 
foi realizada ampla revisão bibliográfica de livros, artigos, documentos oficiais, vídeos e outras fontes, a qual forneceu informações sobre a imigração japonesa no Brasil, a imigração brasileira no Japão e a história do Brasil em diferentes períodos. No caso da pesquisa realizada com foco de análise nos desdobramentos da Shindo Renmei, um apurado registro histórico foi captado através da documentação registrada pela Delegacia Especializada de Ordem Política e Social na década de 1950 no Prontuário $n^{\circ} 108.981$ e disponibilizada no Acervo Histórico de São Paulo. Em ambas as pesquisas, a abordagem empírica esteve presente, por meio de enquete e entrevistas feitas com os grupos em questão.

Dessa forma, pretendeu-se refletir sobre as transformações dos processos de identidade da comunidade japonesa no Brasil e seus desdobramentos mais recentes no Japão. Pretendeu-se, ainda, elucidar e discutir cientificamente um importante episódio dessa comunidade para a história da imigração japonesa e, consequentemente, do Brasil: a Shindo Renmei. O objetivo primordial dessas análises justifica-se pela necessidade de ampliação do debate acerca das percepções de identidade e por trazer subsídios para que esses momentos possam ser revistos a partir da contribuição das ciências humanas e sociais, superando achismos, preconceitos e censuras que acabam por sombrear muitas vezes a compreensão dos fatos vividos.

\section{O contexto da imigração japonesa para o Brasil}

O Japão esteve praticamente isolado do mundo por mais de 200 anos, entre 1639 e 1854, durante o Período Edo ou Tokugawa, que durou de 1603 a $1868 .{ }^{4}$ Suas relações internacionais se resumiam ao comércio com poucos países orientais, sobretudo a China. ${ }^{5}$ Dessa forma, era um país praticamente autossuficiente, independente e conservador.

A partir de 1868, o Japão viveu a revolução Meiji, um marco histórico que tinha como objetivo transformar completamente a sua economia,

4 Sociedade Brasileira de Cultura Japonesa (SBCJ), Uma epopéia moderna: 80 anos imigração japonesa no Brasil, São Paulo: Hucitec, 1992, p. 27.

5 Renato Ortiz, O próximo e o distante: Japão e modernidade-mundo, São Paulo: Brasiliense, 2000, p. 44. 
a fim de ocidentalizá-lo. A passagem de um país feudal para uma nação moderna exigia a rápida industrialização do seu território, o que também acarretou diversos problemas de caráter social. O excesso populacional nas cidades, sem condições de abrigar toda a mão de obra que chegava do campo, gerou um alto índice de desemprego. A situação era agravada pela baixa produtividade agrícola (consequência do êxodo rural) e industrial (resultado do longo período de isolamento), altos tributos e mudanças drásticas e impopulares tomadas pelo governo Meiji, gerando insatisfação em massa entre a população. ${ }^{6}$ Segundo Francisca Isabel Schurig Vieira, a reforma tributária praticada pela Era Meiji no Japão a partir de 1873 prejudicou os agricultores, que eram obrigados a pagar altas taxas de impostos, causando o empobrecimento da população rural e o confisco das terras pelo governo por falta de pagamento dos tributos. ${ }^{7}$

Assim, a partir de 1879, diversas regiões japonesas passaram a conviver com revoltas agrárias. Sem muitas opções para solucionar de forma rápida esse impasse, o governo japonês passou a reconhecer a emigração como necessária para reduzir as tensões sociais. ${ }^{8}$ As opções de nova vida aumentaram exponencialmente com o incentivo de emigração do governo japonês. México, Peru, Bolívia, Austrália, Estados Unidos e Brasil eram alguns dos países receptores. A primeira emigração oficial de japoneses aconteceu em 1868, quando 148 homens solteiros foram recrutados para trabalhar em fazendas de açúcar no Havaí (Estados Unidos). Fugindo da crise social e econômica que aterrorizava o Japão nesse período, os trabalhadores garantiriam não apenas sua própria sobrevivência, mas principalmente de suas famílias, que permaneciam no país, para as quais juntavam e enviavam o máximo de dinheiro possível.

6 Philip Staniford, "Competição e conflito em Tomé-Açu, Pará", in Hiroshi Saito e Takashi Maeyama (orgs.), Assimilação e integração dos japoneses no Brasil (São Paulo: Edusp, Petrópolis Vozes, 1973), p. 33.

7 Francisca Isabel Schurig Vieira, O japonês na frente da expansão paulista: o processo de absorção do japonês em Marília, São Paulo: Pioneira, 1973, p. 29.

8 Usamos a palavra migrar para fazer referência a deslocamentos de maneira geral, tanto internos quanto internacionais, em ambos os sentidos. Usamos imigrar quando os deslocamentos são internacionais e o local de referência é o de destino (imigrantes que vieram para o Brasil) e emigrar igualmente em deslocamentos internacionais mas quando o local de referência é o de origem (emigrados de tal país tornam-se imigrantes no Brasil). Quando tratamos apenas de deslocamentos internos (dentro de um mesmo país), a palavra geralmente usada é migrante, apenas. 
O imperador Meiji também apostava na viagem ao exterior como forma de manter contato com outros povos, abrir possibilidades de negócios, expandir áreas de influência, formar mão de obra especializada, instalar tecnologia de ponta nas suas indústrias e conhecer toda a infraestrutura dos países desenvolvidos.

Enquanto o Japão vivia uma crise econômica e social como resultado da política de abertura das suas fronteiras e rápida industrialização, o governo brasileiro debruçava-se na importação de imigrantes para a exploração de suas terras.

Brasil, assim como Cuba, era um dos poucos países escravocratas do Novo Continente depois de 1808. Assim, o país começou a receber um número muito maior de navios negreiros. Entre 1811 e 1820, o Brasil introduziu 328 mil escravos na cafeicultura, mas a pressão externa para o fim da escravidão levou o governo a promover a imigração europeia. Com o progressivo sufocamento do trabalho escravo no Brasil, que percorreu praticamente todo o século XIX (desde 1810, com uma série de tratados entre Portugal e Inglaterra para a restrição do tráfico negreiro através do Atlântico; passando pelo Bill Aberdeen inglês, de 1845; a Lei Eusébio de Queirós, de 1850; a Lei do Ventre Livre, de 1871; a Lei dos Sexagenários, de 1885; até culminar na Abolição da Escravatura, em 1888), a necessidade de uma alternativa para o trabalho no Brasil foi agravando-se concomitantemente a esses tratados. Aqueles que não podiam custear o alto preço dos escravos, cada vez mais restritos e, portanto, mais caros, começaram a investir na lógica do trabalho livre mediante a imigração, sobretudo europeia. ${ }^{9}$ Atrelada ainda a um projeto de civilização e desenvolvimento do país por meio da melhoria de sua população (ideal do embranquecimento), a prática da importação de braços europeus estendeu-se pelo país como um todo, mas principalmente nas regiões Sul e Sudeste, onde o ciclo econômico do café vivia seu auge e a política imigratória de colonização ganhava força. Pensava-se o Brasil como um país recém-liberto do jugo da colonização, mas com

9 A partir dos primeiros tratados impostos pela Inglaterra, o preço do escravo sobe como consequência da restrição ao tráfico negreiro. Aumentam significativamente também as alternativas não legais de aquisição, como o próprio contrabando, o que por sua vez, inflacionará ainda mais esses preços, impossibilitando a aposta no trabalho escravo daqueles que não podiam competir com essas altas. 
uma população considerada degenerada, que precisava se recompor em termos de povo, havendo a necessidade de formar um povo sadio para uma nação sadia. ${ }^{10}$ Dentro dessa perspectiva, negros, indígenas e mestiços eram indesejados, uma vez que considerados impróprios para o trabalho e para a civilização.

Seguindo essa mesma lógica, a imigração de não brancos para o país estava fora de cogitação. Embasado no pensamento eugênico divulgado por Francis Galton, o projeto de branqueamento racial do povo brasileiro ganha força ao longo do século XX. ${ }^{11}$ Assim, asiáticos e africanos estavam fora dos planos de seleção da população imigrante para a composição sadia do Brasil. O assim chamado elemento amarelo era considerado racialmente inferior e lograva, dessa forma, longas discussões na sociedade brasileira, uma vez que, sendo entendido como mais uma "raça inferior", nos causaria mais problemas do que soluções, pois contribuiria ainda mais para a nossa degenerescência racial, e isso era tudo o que o país não precisava. Em termos de política imigratória e permissões de imigração, no ano seguinte à proclamação da República, 1890, era aprovado o Decreto $n^{\circ} 528$, que:

Regulariza o serviço da introdução e localização de imigrantes na República dos Estados Unidos do Brasil.

\section{PARTE PRIMEIRA}

\section{CAPITULO I}

\section{DA INTRODUÇÃO DE IMIGRANTES}

Art. $1^{\circ}$ É inteiramente livre a entrada, nos portos da República, dos indivíduos válidos e aptos para o trabalho, que não se acharem sujeitos à ação criminal do seu país, excetuados os indígenas da Ásia, ou da África que somente mediante autorização do

10 Lilia Moritz Schwarcz, Retrato em branco e negro: jornais, escravos e cidadãos em São Paulo no fim do século XIX, São Paulo: Companhia das Letras, 1987; O espetáculo das raças: Cientistas, instituições e pensamento racial no Brasil 1870-1930, São Paulo: Companhia das Letras, 1993.

11 Pietra Diwan, Raça pura: uma história da eugenia no Brasil e no mundo, São Paulo: Contexto, 2013. 
Congresso Nacional poderão ser admitidos de acordo com as condições que forem então estipuladas. ${ }^{12}$

Já no século XX, outro fator agravou a escassez de trabalhadores rurais. Em 1902, o governo da Itália proibiu a imigração subsidiada de italianos para o Brasil por meio do Decreto Prinetti em razão dos maus tratos sofridos pelos italianos que chegavam às fazendas de café para o trabalho. ${ }^{13}$ À época, eles representavam a maior corrente imigratória para o país. Para Oliveira, essa proibição do governo italiano foi um dos fatores que contribuíram para o aceite da imigração japonesa no país, pois, pressionado pelos grandes cafeicultores do estado de São Paulo, o governo brasileiro acaba por permitir e mesmo favorecer a consolidação da imigração de outros grupos até então proibidos, como os asiáticos. ${ }^{14}$

Depois de décadas de negociações e do grande celeuma acerca das condições raciais e de inferioridade dos asiáticos, após forte queda da imigração italiana para os campos de café (resultado do Decreto Prinetti) - e fruto de muita astúcia na diplomacia de ambos os países - a imigração japonesa para o Brasil finalmente se inicia em 1908, em pleno século XX, quase um século após a chegada dos alemães, portugueses, italianos e espanhóis (Tabela 1). Ao lado de outros fatores, essa situação colaborou profundamente para um maior estranhamento entre esses diversos grupos e a própria sociedade brasileira, como veremos a seguir.

12 Brasil, "Decreto n. ${ }^{\circ}$ 528, 28/06/1890", Coleção de Leis do Brasil (1890), v. 1, fasc. 4, fl. 1424, $<$ https://bit.ly/2XF9bc3>, acessado em 23/10/2017.

13 O Decreto Prinetti (Giulio Prinetti, Ministro das Relações Exteriores da Itália) foi emitido em 1902 pelo Comissariado Geral da Emigração na Itália. Ocorre como consequência de um relatório recebido pelo governo italiano que reportava os maus tratos recebidos pelos imigrantes italianos no Brasil que trabalhavam nas fazendas de café. Cf. Ângelo Trento, Do outro lado do Atlântico: um século de imigração italiana no Brasil, São Paulo: Nobel, 1988.

14 Adriana Capuano de Oliveira, "Japoneses no Brasil ou brasileiros no Japão: a trajetória de uma identidade em um contexto migratório" (Dissertação de Mestrado, Universidade Estadual de Campinas, 1997), p. 25. 
Tabela 1 - Entrada de imigrantes (1820-1929)

\begin{tabular}{cccccccc}
\hline $\begin{array}{c}\text { Ano/ } \\
\text { País }\end{array}$ & Portugal & Itália & Alemanha & Espanha & Japão & Outros & Total \\
\hline $1820-29$ & - & - & 1.984 & - & - & 7.112 & 9.096 \\
$1830-39$ & 261 & 180 & 207 & - & - & 2.021 & 2.669 \\
$1840-49$ & 491 & 5 & 2.139 & 10 & - & 2.347 & 4.992 \\
$1850-59$ & 63.272 & 24 & 15.806 & 181 & - & 28.843 & 108.126 \\
$1860-69$ & 53.618 & 4.916 & 16.514 & 633 & - & 34.398 & 110.079 \\
$1870-79$ & 67.609 & 47.100 & 14.627 & 3.940 & - & 60.609 & 193.885 \\
$1880-89$ & 104.491 & 276.724 & 19.201 & 29.066 & - & 23.997 & 453.079 \\
$1890-99$ & 215.354 & 670.508 & 17.034 & 164.193 & - & 115.929 & 1.183 .018 \\
$1900-09$ & 195.586 & 221.394 & 13.848 & 121.604 & 861 & 82.145 & 635.438 \\
$1910-19$ & 318.481 & 137.868 & 61.902 & 181.696 & 27.732 & 136.374 & 863.714 \\
$1920-29$ & 301.913 & 106.835 & 75.801 & 81.931 & 58.284 & 221.881 & 846.645 \\
Total & 1.321 .076 & 1.465 .554 & 239.063 & 583.254 & 86.577 & 715.656 & 4.410 .741 \\
\hline Fonte: Mirador Internacional, "Migração" apud Sociedade Brasileira de Cultura Japonesa, Uma epopéia \\
moderna, p. 24.
\end{tabular}

\section{A imigração japonesa até a Guerra: percepções de identidade}

Os primeiros 781 imigrantes japoneses chegaram ao Brasil em 18 de junho de 1908, quando aportou em Santos, litoral paulista, o navio Kasato Maru. A imigração para o trabalho envolve muitas expectativas: a do viajante, que espera melhorar a condição da sua própria vida e de seus entes; a dos familiares, que apostam todas as fichas naquele que viaja e envia remessas de dinheiro para os que ficam; e a de vizinhos e amigos, que desejam saber sobre o sucesso do imigrante para, talvez, seguir os mesmos passos. No caso dos imigrantes japoneses, além da esperança dos entes mais próximos, eles também sofriam grande pressão por parte do governo do seu país, que igualmente acreditava na possibilidade de melhoria da condição social e econômica por meio da emigração.

Além de estar representando toda a nação, cada um dos japoneses deveria se esforçar ao máximo para não desapontar o imperador Meiji, 
considerado um deus vivo. No novo país, o japonês deveria comportar-se de forma exemplar, trabalhar arduamente e manter a honra e a dignidade em qualquer circunstância, pois era um representante do "Grande Império". A orientação foi dada diversas vezes pelas autoridades nipônicas, inclusive antes do Kasato Maru deixar o porto de Kobe, na tarde do dia 28 de abril de 1908, quando o deputado Gonta Doi, representando o governo japonês, discursou:

Vocês estão seguindo para um outro país e não devem se esquecer de que cada um representa o Japão: cada um está carregando seu próprio país consigo. É necessário que todos se encarreguem de não manchar a honra japonesa ou o nome de sua Pátria. Se não forem capazes de viver condignamente, não pensem em voltar. Tenham vergonha disso e morram por lá. ${ }^{15}$

Junto às inúmeras dificuldades de adaptação que estariam por vir, os japoneses carregavam ainda a crença na superioridade racial e cultural de seu povo, herança do fortalecimento do sentimento de unidade entre os japoneses historicamente construída. Com a chegada do período Meiji, a necessidade de recriação do Japão com base no modelo de estado-nação ocidental acirrou ainda mais essas crenças e sentimentos. Assim, os japoneses deveriam trabalhar e lutar para a modernização do país em busca da sua prosperidade.

A concepção de supremacia e raridade, definida como uniqueness, foi alcançada por meio da construção de uma ideia de nação, moldada a partir da multiplicação de histórias que glorificam o passado e que projetam o futuro da pátria. ${ }^{16}$ Assim agiram os líderes Meiji. Reforçaram a originalidade cultural e racial dos japoneses, a homogeneidade cultural, principalmente por meio da língua, o passado de glórias e a imagem do imperador - singular por descender de única linhagem. Visando ao futuro, priorizaram a educação e as forças armadas. Diversos eram os

15 "BRASIL-JAPÃO: aqui começa uma história de 70 anos", O Estado de S. Paulo, São Paulo, 18 jun. 1978, p. 161, <https://bit.ly/35nY5vY>, acessado em 14/01/2016.

16 Claude Lévi-Strauss, A antropologia diante dos problemas do mundo moderno, São Paulo: Companhia das Letras, 2012, p. 90. 
discursos que ligavam um passado vitorioso a um futuro promissor em torno do "Grande Japão". ${ }^{17}$

A crença dos japoneses na origem divina do imperador Meiji facilitava a criação de uma liderança simbólica. Ele estaria ligado ao cultivo do arroz, já que, segundo a tradição, os deuses estão dentro dos grãos de arroz. Descendente de uma deusa, Meiji é uma mistura de xamã e líder político. ${ }^{18}$ Outro orgulho comum entre os japoneses era a invencibilidade do seu poderoso exército, que se mantivera invicto por mais de 2.600 anos até ser derrotado durante a Segunda Guerra Mundial. ${ }^{19}$

Esse tardio processo imigratório japonês, que começou muitas décadas depois da chegada dos italianos, alemães, espanhóis e outros trabalhadores estrangeiros (Tabela 1), provocou especificidades de todas as partes. ${ }^{20}$ Os demais imigrantes, enturmados com seus pares, zombavam dos japoneses como passatempo; já os japoneses não se esforçavam para aprender a língua portuguesa, mantinham seus costumes, ensinavam apenas o idioma pátrio aos filhos etc. Tentavam viver como se nunca tivessem saído do Japão, mesmo porque acreditavam que em breve voltariam para a terra natal e não queriam ver os filhos prejudicados na escola. A vida no campo, longe dos centros urbanos, facilitava o isolamento dessa comunidade.

\section{O perigo amarelo e os anos que antecederam a guerra: a Assembleia Constituinte de 1933 e a Lei de Cotas de 1934}

No início da década de 1930, o chefe do governo provisório, Getúlio Vargas, presidente eleito pelo voto indireto e ditador, enfrentava um país de muitas incertezas no cenário econômico. A crise mundial instalada pela queda da bolsa de valores de Nova Iorque, em 1929, afetava o Brasil, que não tinha para onde exportar seus produtos, levando os fazendeiros à superprodução de café e, consequentemente, à ruína. As dificuldades

17 Strauss, A antropologia, p. 93.

18 Celia Sakurai, "Imigração tutelada: os japoneses no Brasil" (Tese de Doutorado, Universidade Estadual de Campinas, 2000), p. 40.

19 Edward Behr, Hiroito: por trás da lenda, São Paulo: Globo, 1991, p. 13.

20 Oliveira, "Japoneses no Brasil ou brasileiros no Japão", p. 30. 
financeiras cresciam e geravam desemprego nas cidades. Nessa década, ganhou força no Brasil a corrente autoritária, que assumiu a modernização conservadora. Em um país desarticulado, o Estado deveria organizar a nação para promover, dentro da ordem, o desenvolvimento econômico e o bem-estar geral. "O Estado autoritário poria fim aos conflitos sociais, às lutas partidárias, aos excessos da liberdade de expressão que só serviam para enfraquecer o país". ${ }^{21}$

As autoridades preocupavam-se em formar uma elite intelectualmente mais bem preparada e havia desde 1920 tentativas de reforma no ensino, sendo o combate ao analfabetismo e "a preocupação de integrar os imigrantes" a principal pauta na educação paulista. Seguindo o exemplo de países como os Estados Unidos - que haviam proibido a imigração asiática como um todo, notadamente pela discriminação norte-americana contra os chineses - autoridades brasileiras apresentaram projetos de lei para inibir a entrada desses trabalhadores. Alegavam, para tal, o alto custo da mão de obra, uma vez que as viagens eram subsidiadas pelo governo de São Paulo e os japoneses não cumpriam com os contratos de trabalho, pois fugiam das fazendas em busca de melhores oportunidades. A emergência do Japão enquanto potência militar na Ásia e a disparidade dos aspectos culturais e físico-raciais dos japoneses também eram motivo para rejeitá-los, sendo essas características físicas uma das mais proeminentes, de acordo com os critérios eugênicos e a discussão apresentada no primeiro item ("O contexto da imigração japonesa para o Brasil").

Antes mesmo do governo provisório de Vargas, em 1925, o governo paulista deixara de subsidiar as viagens dos japoneses, as quais passaram a ser financiadas pelo próprio governo nipônico. Contudo, o plano de diminuir essa imigração não obteve êxito. Foi nesse período, entre 1924 e 1934, que se observou o maior número de japoneses desembarcando no país: 121.921, de acordo com o Anuário Estatístico do Brasil, IBGE, de 1951. O Brasil passou, nessa época, a ser o país com a maior comunidade japonesa fora do Japão, título que mantém até os dias atuais.

A concorrência da mão de obra estrangeira diante da nacional era outra inquietação do governo provisório getulista. O Decreto n ${ }^{\circ} 19.482$,

21 Boris Fausto, História do Brasil, São Paulo: Fundação do Desenvolvimento da Educação, 1995, p. 357. 
de 12 de dezembro de 1930, alterou as condições de acesso de imigrantes ao país, justificando tal ato pela necessidade de aliviar o desemprego urbano, resultado da crise cafeeira e cambial instaurada pela quebra da bolsa de Nova Iorque no ano anterior. O decreto considerava que "uma das causas do desemprego se encontra na entrada desordenada de estrangeiros, que nem sempre trazem o concurso útil de quaisquer capacidades, mas frequentemente contribuem para o aumento da desordem econômica e da insegurança nacional". ${ }^{22} \mathrm{O}$ documento autorizava apenas a entrada dos imigrantes solicitados pelo Ministério do Trabalho, Indústria e Comércio para serviços agrícolas e dos portadores de "bilhetes de chamada" (emitidos por parentes a famílias de agricultores com colocação garantida) e instituía a "Lei dos $2 / 3$ ", que obrigava as empresas a comprovarem que seu quadro de empregados era formado por pelo menos dois terços de brasileiros natos. Essa norma não atingia diretamente os japoneses, os quais trabalhavam sobremaneira na zona rural.

A partir daí as restrições aos estrangeiros não pararam mais. A xenofobia e a censura ficavam camufladas, porém, sob o discurso econômico, de empregabilidade aos nacionais, e sob o discurso nacionalista, de união e fortalecimento da nação brasileira.

A abertura da Assembleia Nacional Constituinte, em 1933, marcou o rompimento com a República Velha e reforçou o caráter institucional das discussões acerca da mão de obra estrangeira. A partir desse momento, os debates favoráveis e contrários à imigração ganharam repercussão entre os parlamentares e a imprensa. Formou-se, na Assembleia, uma bancada antinipônica, a qual manifestava e argumentava contra a presença dos japoneses e seus descendentes no Brasil. O sanitarista Arthur Neiva, parlamentar à frente do movimento antinipônico, considerava o imigrante japonês "elemento indesejável" para a "formação da nacionalidade" por, entre outros motivos, chegar doente ao Brasil e ser desqualificado "do ponto de vista antropo-estético". ${ }^{23}$

22 Brasil, "Decreto n. ${ }^{\circ}$ 19.482”, Diário Oficial da União, Brasília, DF, 12 dez. 1930, Seção 1, p. 1603 (republicação).

23 Priscila Nucci, “Algumas manifestações do antiniponismo brasileiro (1934-1945)”, Cadernos Arquivo Edgard Leuenroth, v. 15, n. 27 (2009), pp. 311-350, <https://bit.ly/312xvVS>, acessado em 23/10/2017. 
A Constituinte de 1934 incluía a principal medida contra os imigrantes japoneses. O documento estabelecia uma cota para imigração. O Brasil passava a aceitar apenas $2 \%$ do total de ingressantes de cada nacionalidade no país nos últimos 50 anos. Apesar de não fazer menção à raça ou à nacionalidade, dada a força do movimento antinipônico na Assembleia, era clara a tentativa de inibir a chegada de mais japoneses, que foram bastante prejudicados por serem a imigração em massa mais recente. Arthur Neiva se baseou em um estudo de Hubert Herring que apontava o Brasil como vulnerável a uma ameaça japonesa, pois, apesar de possuírem "muitas qualidades culturais e também disciplina, organização e capacidade de trabalho", a população japonesa já estava próxima a 200 mil e vinha crescendo. ${ }^{24}$

Posteriormente, em 1938, outra lei tinha como objetivo controlar as "ideologias estranhas" por meio do uso da língua portuguesa no ensino de todas as matérias, inclusive nas escolas rurais de comunidades estrangeiras, as quais deveriam ter apenas professores brasileiros natos e utilizar nas aulas material didático completamente escrito em português. ${ }^{25}$

Os imigrantes nipônicos tornavam-se, assim, cada vez mais isolados da sociedade brasileira. De um lado o espírito Meiji com o qual chegavam, e que os compelia ao isolamento entre si; de outro, as dificuldades de inserção cultural (devido às grandes diferenças de costumes entre os dois países, e principalmente à língua); e ainda o cerco que viviam graças a essas restrições impostas pelo governo. As comunidades formadas por trabalhadores estrangeiros foram chamadas de "quistos" étnicos ou raciais, alarma Endrica Geraldo. Segundo a autora, "grupos imigrantes que podiam ser caracterizados pelo isolamento racial e cultural são descritos como quistos étnicos e investigados pelo Conselho de Imigração e Colonização". ${ }^{26}$ Para combater o "perigo estrangeiro", notadamente o "perigo amarelo", o governo

24 Endrica Geraldo, “O combate contra os 'quistos étnicos': identidade, assimilação e política imigratória no Estado Novo”, Locus, v. 15, n. 1 (2009), pp. 171-187, <www.ufjf.br/locus/ files/2010/02/337.pdf>, acessado em 08/05/2015.

25 Fernando Morais, Corações sujos, São Paulo: Companhia das Letras, 2011, p. 45.

26 Geraldo, “O combate”, p. 171. 
passou a "fiscalizar e nacionalizar os núcleos que possuíam escolas e imprensa em língua estrangeira". ${ }^{27}$

Segundo Tomoo Handa, com a instalação do Estado Novo, os japoneses acreditavam que as restrições pelas quais passavam seriam eternas. Alguns reagiram fortalecendo ainda mais o sentimento japonês, mas, ao mesmo tempo, aumentava o número de nipodescendentes que repudiava o nacionalismo japonês, afastando-se dele e "acaboclando-se". ${ }^{28}$ Entre os que ponderavam a situação do ponto de vista nacional estavam os imigrantes com filhos nascidos no Brasil. Para os demais, era mais difícil adaptar-se ao modo de vida brasileiro dada a grande diferença entre os costumes. Assim, viviam confinados "na sociedade dos conterrâneos, reprimindo sentimentos e não conseguindo aceitar a situação". Entre esses, intensificou-se o amor pela terra natal. ${ }^{29}$

Entre 1938 e 1939 foi promulgada a maior parte dos decretos de repressão às atividades estrangeiras no Brasil. As medidas de nacionalização - como o fechamento de escolas estrangeiras, a proibição do ensino em outra língua que não a portuguesa, e a proibição da circulação de impressos e da importação de livro didático em língua estrangeira - representavam "a interrupção de um processo cultural que vinha sendo mantido há quase um século", já que os alemães começaram a emigrar para o Brasil em 1820. ${ }^{30}$ Para os imigrantes japoneses, contudo, essas medidas foram ainda mais drásticas, visto que a sua imigração foi a mais recente dentre as demais e os fatores de ambos os lados favoreciam um maior isolamento em "comunidades de iguais" (espírito Meiji, sonho de retorno, dificuldades culturais e linguísticas, política de eugenia, censura e repressão).

27 Geraldo, "O combate", p. 176.

28 Tomoo Handa, O imigrante japonês: história de sua vida no Brasil, São Paulo: T. A. Queiroz Editor, 1987, p. 598.

29 Handa, O imigrante japonês, p. 600.

30 Simon Schwartzman, Helena Maria Bousquet Bomeny, Vanda Maria Ribeiro Costa, "Tempos de Capanema", São Paulo: Paz e Terra, 2000, pp. 166-167. 


\section{Os duros anos da Guerra: repressão, censura e isolamento}

Em 1942, a comunidade japonesa somava 188.615 pessoas no Brasil. ${ }^{31}$ No dia 28 de janeiro do mesmo ano, data em que o Brasil declarou apoio aos Estados Unidos, as relações diplomáticas entre Brasil e os países do Eixo foram interrompidas. No dia seguinte, a Superintendência de Segurança Política e Social de São Paulo publicou a portaria que regulamentaria a atividade dos estrangeiros provenientes da Alemanha, Itália e Japão, como aponta Fernando Morais. ${ }^{32}$ Entre as determinações, esse grupo de imigrantes estava proibido de disseminar escritos nos seus respectivos idiomas; cantar o hino nacional dos seus países; falar o idioma pátrio em lugares públicos; reunir-se em comemoração, mesmo que fosse dentro de suas próprias casas; discutir sobre a situação internacional em lugar público; usar armas, mesmo que legalmente adquiridas; mudar de residência sem comunicação prévia às autoridades; e viajar sem salvo-conduto fornecido pela Superintendência.

"Com o objetivo de fiscalizar os súditos do Eixo e protegê-los", o estado brasileiro decidiu retirar os imigrantes alemães, italianos e japoneses de áreas litorâneas e regiões de grande concentração de estrangeiros em diversos estados do país. ${ }^{33}$ Fernando Morais relata que na primeira vez que os japoneses foram despejados da Rua dos Estudantes e da Rua Conde de Sarzedas, no bairro da Liberdade, no fim de janeiro, os caminhões da Força Pública e da Delegacia de Ordem Política e Social (Deops) chegaram durante a noite. ${ }^{34}$ Os oficiais distribuíram aos moradores cópias da portaria do Deops justificando a evacuação, que deveria se dar em doze horas, "por razões de segurança nacional". ${ }^{35}$ Ao serem questionados para onde deveriam se mudar, os policiais responderam: "Isso não é problema nosso". Em poucas horas, 400 famílias estavam fora de suas casas. "Centenas de homens e mulheres, inclusive crianças e ido-

31 IBGE, Anuário Estatístico do Brasil: 1954: ano 15, Rio de Janeiro: IBGE, 1954, p. 59, <https:// bit.ly/2MvPFtV>, acessado em 30/10/2015.

32 Morais, Corações sujos, pp. 45-46.

33 SBCJ, Uma epopéia moderna, p. 261.

34 Liberdade é um bairro de São Paulo notadamente conhecido por concentrar muitos nipônicos.

35 Morais, Corações Sujos, p. 52. 
sos, muitos deles empregados ou donos de pequenos negócios a poucos metros de suas casas, terminaram a noite acampados em casas de amigos ou de parentes, ou hospedados em modestas pensões". ${ }^{36}$ A retirada dos japoneses de suas próprias casas se repetiria mais vezes.

A tentativa do governo brasileiro de acabar com o "pequeno Japão dentro do Brasil", no entanto, surtiu efeito contrário. ${ }^{37}$ Ao fechar escolas e proibir a circulação de periódicos em língua japonesa, como veremos adiante, os imigrantes japoneses se fortaleciam ainda mais em torno de suas manifestações culturais. No intuito de resistir silenciosamente à censura brasileira, eles formavam associações culturais e esportivas e outros tipos de grupos onde os hábitos e ensinamentos japoneses tivessem a chance de sobreviver, mesmo que na clandestinidade.

Autoridades da época viam a dificuldade da formação nacional devido às inúmeras correntes imigratórias. Em 1906, Silvio Romero já alertava para o "perigo de se criar nacionalidades outras dentro do Brasil". ${ }^{38}$ As discussões dos parlamentares sobre a "invasão estrangeira no Brasil" apontavam para a urgente necessidade de reformulação do ensino primário e da criação de escolas nacionais. Nunca houve, apontam Schwartzman, Bomeny e Costa, "quem defendesse para o país a constituição de uma sociedade culturalmente pluralista, que desse a cada nacionalidade aqui aportada e aos próprios habitantes primitivos do país as condições de manter e desenvolver sua própria identidade étnica e cultural". ${ }^{39} \mathrm{O}$ projeto educacional objetivava homogeneizar a população por meio do idioma português, do ensino da geografia e da história do Brasil e da formação cívica e moral, além de outros subsídios peculiares brasileiros, como a arte popular e o folclore. Dessa forma, as novas gerações ganhariam "a feição dos sentimentos e ideias coletivos, em que afinal o senso de unidade e de comunhão nacional repousam". ${ }^{40}$

36 Morais, Corações Sujos, p. 52.

37 SBCJ, Uma epopéia moderna, p. 236.

38 Schwartzman et al., Tempos de Capanema, p. 90.

39 Schwartzman et al., Tempos de Capanema, p. 90.

40 Manuel Bergstrom Lourenço Filho, "Conferência na Escola do Estado-maior do Exército" (27/10/1939) apud Schwartzman et al., Tempos de Capanema, p. 93. 
A escola japonesa era muito presente nas colônias desses imigrantes. Na nippon gakko, como a escola japonesa era conhecida antes da Segunda Guerra, as crianças recebiam a educação formal e aprendiam os valores japoneses. Maeyama aponta que a escola era o local onde as crianças, os jovens e até mesmo os adultos tornavam-se "japoneses", ou seja, "um real ser humano". ${ }^{41}$ No local, fortaleciam o Yamato damashii, ${ }^{42}$ o espírito japonês. Consideradas o centro de culto ao imperador em qualquer comunidade japonesa no Brasil, as escolas eram administradas por associações japonesas locais e possuíam o retrato do imperador para ser venerado, além da Escritura Imperial sobre Educação, lida como um sutra e guardada como uma relíquia, pois acreditava-se que nela se incorporavam os princípios e virtudes máximos da niponicidade. ${ }^{43}$ Por realizar práticas de adoração ao imperador, a escola era apreciada como um centro espiritual da comunidade, abrigando também reuniões, atividades de jovens e cerimônias de todos os tipos, como celebração do ano novo, dia do imperador e casamentos. ${ }^{44}$ Portanto, o fechamento das escolas significou mais do que o fim da educação japonesa para os filhos. Foi o fim de todas as atividades sociais, principalmente do culto ao imperador.

Diante dessa situação-limite, os japoneses resolveram burlar a norma e camuflar suas escolas. Segundo Tomoo Handa, as crianças chegaram a ser reunidas em depósitos ou em barrancos nas montanhas para dificultar o acesso de pessoas que pudessem denunciar a prática ilegal. O local da aula era vigiado em revezamento e, caso alguém de fora aparecesse, os professores se escondiam ou pegavam uma enxada e come-

41 Takashi Maeyama, "Ancestor, Emperor and Immigrant: Religion and Group Identification of the Japanese in Rural Brasil (1908-1950)", Journal of Interamerican Studies and World Affairs, v. 14, n. 2 (1972), pp. 151-182.

42 De acordo com Fernando Morais (Corações sujos, p. 74), o Yamato damashii era o "padrão de comportamento ideal que o militarismo ultranacionalista japonês adotara como doutrina". No Brasil, ele foi assumido pelos imigrantes japoneses durante a Segunda Guerra Mundial para reforçar sua identidade como grupo, mesmo diante de situações de fracasso, como a derrota na guerra. Cf. Rogério Dezem, "Hi-no-maru manchado de sangue: a Shindo Renmei e DOPS/ SP”, in Maria Luiza Tucci Carneiro e Marcia Yumi Takeuchi (orgs.), Imigrantes japoneses no Brasil: trajetória, imaginário e memória (São Paulo: Edusp, 2011), p. 10. Outra tradução de Yamato damashii dada por Dezem é "espírito de imbatividade", em Matizes do 'Amarelo': elementos formadores do imaginário sobre o japonês no Brasil, São Paulo: Arquivo Público do Estado, Universidade de São Paulo, 2005, p. 5.

43 Ortiz, O próximo e o distante, p. 56.

44 Maeyama, “Ancestor, Emperor”, p. 170. 
çavam a arar a terra enquanto as crianças fingiam brincar. ${ }^{45}$ De acordo com Hatanaka, mais de duzentas escolas japonesas foram fechadas no estado de São Paulo e muitos professores foram denunciados pelo exercício de atividades ilegais durante o Estado Novo. ${ }^{46}$

Os imigrantes japoneses também sofreram com o fechamento das publicações em sua língua, o confisco de aparelhos de rádio e a negação de todos os demais meios de comunicação (até mesmo a troca de cartas com os familiares e amigos que haviam permanecido no país de origem foi proibida).

Se a situação era ruim para aqueles que viviam no interior, era ainda pior para os que residiam na capital paulista, principalmente para os proprietários de livrarias do bairro da Liberdade, onde os caminhões da Força Pública estacionavam pelo menos uma vez por semana para fazer uma varredura. "Os soldados desciam, enchiam caixas com livros e revistas impressos em japonês - não importava o conteúdo, nem os policiais conseguiam ler o que estava escrito neles - jogavam o 'material subversivo' na carroceria do veículo e sumiam". ${ }^{47}$

O que as autoridades brasileiras talvez não previssem com a proibição dos meios de comunicação em língua japonesa era o início de uma instabilidade nessa comunidade. Como muitos não dominavam o idioma português, os imigrantes ficaram totalmente alheios aos acontecimentos do Brasil, do Japão e, principalmente, sobre o desenrolar da Segunda Guerra Mundial.

Uma enquete retrospectiva sobre as notícias no período da guerra, realizada por Izumi e Saito em 1952, apontou quais fontes de informação tiveram mais crédito entre os japoneses instalados no Brasil. ${ }^{48}$ Os resultados mostraram que apenas 3\% dos entrevistados tiveram a imprensa brasileira como fonte primária de informação; a rádio receptora de ondas

45 Handa, O imigrante japonês, p. 622.

46 Maria Lúcia Eiko Hatanaka, O processo judicial da Shindo-Renmei: um fragmento da história dos imigrantes japoneses no Brasil, São Paulo: Fundação Japão, 2002, p. 36.

47 Morais, Corações sujos, p. 53.

48 Yorihiko Kumasaka e Hiroshi Saito, "Kachigumi: uma delusão coletiva entre os japoneses e seus descendentes no Brasil”, in Hiroshi Saito e Takashi Maeyama (orgs.), Assimilação e integração dos japoneses no Brasil (São Paulo: Edusp, 1973), p. 452. 
curtas (mantidas ilegalmente nas residências) e as publicações clandestinas foram o canal de informação para $29 \%$ deles (14\% para rádio e $15 \%$ para as publicações); $64 \%$ se valeram principalmente de informações oralmente transmitidas e $4 \%$ não puderam responder.

Da mesma forma que o governo brasileiro proibiu as escolas e os veículos de informação em japonês, também foram proibidas as associações, os clubes e a formação de quaisquer grupos, sob quaisquer denominações, que reunissem imigrantes provenientes dos países do Eixo. Mas muitas associações continuaram funcionando clandestinamente durante a guerra. De acordo com Fernando Morais, os japoneses criaram cerca de trinta associações até 1942 e quase todas cultuavam valores patrióticos. ${ }^{49}$ Diante de tanta opressão e restrições, a vida no Brasil se tornou ainda mais difícil para os imigrantes japoneses, alemães e italianos. Foi nesse período, a partir de 1942, descreve Vieira, que os japoneses "organizaram grupos de controle, visando manter a coesão e solidariedade étnica". ${ }^{50}$

As notícias sobre o avanço dos soldados norte-americanos no território japonês não chegavam aos imigrantes que viviam no Brasil, muitos dos quais não liam os jornais em português, tendo acesso somente às informações autorizadas pelo governo japonês: "proclamações patrióticas e ufanistas", aponta Jorge Okubaro. ${ }^{51}$ Situação comum nas guerras, o Japão também disseminava comunicações desencontradas e mentirosas. Na realidade, os imigrantes japoneses desejavam mesmo ouvir sobre a vitória do Japão, ainda que falsa. Okubaro lembra que essas informações davam ânimo aos japoneses e estimulavam seu patriotismo. Além disso, não precisavam abaixar a cabeça para as provocações maldosas dos brasileiros. "Por isso, informações sobre sucessivas derrotas japonesas no terreno militar, que contrariavam sua crença na indestrutibilidade do império japonês e na sua invencibilidade, seriam consideradas mentirosas, por serem indesejadas". ${ }^{52}$

A Segunda Guerra Mundial chegara ao fim e, pela primeira vez na história, o imperador realizava um pronunciamento na rádio. Era so-

49 Morais, Corações sujos, pp. 102-103.

50 Vieira, Ojaponês, p. 238.

51 Jorge Okubaro, O súdito: (Banzai, Massateru!), São Paulo: Terceiro Nome, 2006.

52 Okubaro, $O$ súdito, p. 253. 
bre a derrota japonesa, mas, aqui no Brasil, era como se ele declarasse a vitória. Depois de corridos diversos boatos, muitos japoneses foram às ruas como se celebrassem o fim da guerra e algumas famílias começaram a fazer as malas para o tão sonhado retorno à pátria. Acreditava-se que logo o governo japonês enviaria navios para levá-los de volta ao Japão e aos novos territórios conquistados pela nação durante a guerra. Kumasaka e Saito lembram que durante essa inquietação pelo repatriamento, houve um surto de movimentos ultranacionalistas, pois, com a falta de vigilância por parte do governo brasileiro, os japoneses aproveitaram para fortalecer as organizações de cunho patriótico e recrutar membros. ${ }^{53}$

A polícia havia percebido há algum tempo a atividade de japoneses suspeitos que propagavam a vitória de se país quando, nas investigações, a Deops interceptou um panfleto datado de julho de 1945 concretizando a existência da Shindo Renmei. Os membros da organização afirmavam que a "Shindo Renmei se destinava a dirigir a colônia pelo verdadeiro 'Caminho dos súditos', de modo a conservar acesa a chama eterna do amor pátrio e da fidelidade ao Imperador, destinando-se, além disso, a zelar pelos interesses gerais da colônia". ${ }^{4}$

A partir da descrença da maior parte dos japoneses na derrota do Japão na guerra, formaram-se dois grupos dentro da comunidade, aos quais a polícia chamou de "facções": os vitoristas ou kachigumi e os derrotistas ou makegumi. Os primeiros acreditavam cegamente na vitória do Japão - muitos membros da Shindo Renmei ou de outras associações de caráter ultranacionalista - enquanto os derrotistas, japoneses mais cultos, como apontam as autoridades policiais, muitas vezes liam os jornais em português e estavam mais integrados à sociedade brasileira, sendo vistos pelos primeiros como traidores da pátria por divulgarem a derrota. Foram inúmeras as tentativas de comprovar a vitória japonesa pelos ultranacionalistas, estimados em 100 mil pessoas ou $80 \%$ da comunidade na época, que chegaram, segundo os policiais, a forjar notícias para demonstrar

53 Kumasaka e Saito, "Kachigumi”, pp. 452-454.

54 Inquérito policial Shindo-Renmei, 11/03/1946 a 25/10/1947, Delegacia Especializada de Ordem Política e Social (DOPS), Prontuário no 108981, de 23/05/1950, v. 2, p. 12. 
um fictício sucesso da pátria, o que faziam deturpando e modificando datas, dados, textos e fotografias de impressos reais. ${ }^{55}$

A polícia política tomou conhecimento da contrapropaganda realizada pelos considerados derrotistas, que, por meio de panfletos, alertavam os conterrâneos sobre os verdadeiros fatos da guerra. Contra esses japoneses que tentavam elucidar a verdade, a Shindo Renmei passou a fazer várias ameaças de morte.

Foram contabilizados, entre março e agosto de 1946, no mínimo 37 atentados a tiros de revólver ou à bomba, resultando em quatorze mortes (todas as vítimas eram makegumi). Entre setembro e dezembro do mesmo ano, 177 japoneses tiveram sua expulsão do território nacional decretada depois de sucessivos decretos presidenciais. Como medida provisória, eles foram presos na Ilha Anchieta, no litoral paulista, mas muitos acabaram sendo soltos, uma vez que nenhum dos dois governos, brasileiro e japonês, estavam dispostos a arcar com os gastos da extradição. ${ }^{56}$ No total, foram atribuídos à Shindo Renmei 23 assassinatos de japoneses. ${ }^{57}$

É importante registrar a prisão em massa de japoneses inocentes, que não praticaram nenhum assassinato ou atentado. Seu único "crime" havia sido reunir amigos em casa, ler livros em japonês ou usar a língua nativa, a única que sabiam falar. A repressão e a intolerância policiais certamente contribuíram para o fortalecimento do espírito japonês entre os imigrantes perseguidos, como reflete Dezem. ${ }^{58}$

Quase dois anos após o fim da guerra, em junho de 1947, japoneses considerados derrotistas pela Shindo Renmei organizaram uma campanha de solidariedade às vítimas dos combates no Japão, enviando, assim, mantimentos e roupas ao país. Essa foi a primeira ação que reuniu makegumi e kachigumi em um mesmo objetivo. "Recordam os líderes da coletividade, numa visão retrospectiva, que esse movimento de socorro constituiu o método mais efetivo para

55 Inquérito policial Shindo-Renmei, 05/04/1946 a 28/01/1950, Delegacia Especializada de Ordem Política e Social (DOPS), Prontuário nº 108981, de 23/05/1950, v. 3, p. 268.

56 Kumasaka e Saito, "Kachigumi", p. 457-458.

57 Morais, Corações sujos, p. 331.

58 Rogério Dezem, Shindô Renmei: terrorismo e repressão: Inventário Deops: módulo III: japoneses, São Paulo: Arquivo do Estado, Imprensa Oficial, 2000. 
aliviar a tensão entre os dois grupos e, talvez, tenha ajudado muitos japoneses a tomar consciência da realidade". ${ }^{59} \mathrm{O}$ tempo foi o principal conciliador dentro da comunidade japonesa. Com o passar dos meses, o restabelecimento das comunicações e a chegada dos 1.500 imigrantes japoneses da primeira leva do pós-guerra em 1953 - e seus relatos sobre a penúria, a angústia, a cólera que haviam suportado e as migalhas que se tornara seu país -, os kachigumi finalmente entenderam a realidade e se envergonharam profundamente de todos os desencontros que promoveram. ${ }^{\mathbf{6 0}}$

Francisca Isabel Schurig Vieira aponta que a Shindo Renmei era vista simplesmente como uma sociedade secreta e terrorista pela polícia. ${ }^{61}$ Por isso, sofreu violenta repressão. Mas a Liga do Caminho dos Súditos não se resumia a isso, tampouco a um grupo que negava a derrota japonesa por falta de acesso aos meios de comunicação. ${ }^{62}$ Para a autora, essa negação se dava em um nível mais profundo, tratando-se de um relacionamento de subordinação de todas as partes: as autoridades brasileiras que repreendiam, os vizinhos brasileiros e de outras nacionalidades que zombavam, os jornais brasileiros que difamavam e os japoneses esclarecidos que, na visão dos vitoristas, traíam a pátria. Essa subordinação foi pacientemente aceita por se tratar de uma situação passageira, a qual, para os imigrantes japoneses, seria superada com a vitória da pátria-mãe na guerra, porém a derrota do país nos combates faria com que esse sofrimento temporário se perpetuasse. Logo, ao negarem a derrota japonesa na guerra, refutavam, sobretudo, essa condição permanente. Para Takashi Maeyama, o movimento vitorista-derrotista foi a "última manifestação direta do 'antiaculturacionismo' contra a crescente tendência de assimilação e acomodação à sociedade brasileira" ${ }^{63}$

59 Kumasaka e Saito, “Kachigumi”, p. 459.

60 Dezem, Inventário Deops, p. 84.

61 Vieira, Ojaponês, p. 239.

62 A Liga do Caminho dos Súditos é uma das traduções para Shindo Renmei apresentada pelo Inquérito Policial da Shindo Renmei.

63 Takashi Maeyama, "O antepassado, o imperador e o imigrante: religião e identificação de grupo dos japoneses no Brasil rural (1908-1950)", in Hiroshi Saito e Takashi Maeyama (orgs.), Assimilação e integração dos japoneses no Brasil (São Paulo: Edusp, 1973), p. 416. 


\section{Redefinindo a identidade: não há mais retorno possível!}

O desfecho da Segunda Guerra Mundial foi algo absolutamente inesperado para a maioria dos imigrantes japoneses residentes no Brasil, que nunca poderiam imaginar o Império do Sol Nascente derrotado em uma guerra. Podemos considerar esse momento como um verdadeiro "divisor de águas" dessas expectativas e mesmo das suas percepções de identidade.

A ideia de retornar à pátria de origem, ao país de origem, à sua casa natal, onde parte de seus familiares ficaram, é constante nas migrações de uma forma geral. Isso é verdade tanto para as migrações do século XIX e XX, como para as atuais. É muito difícil admitir para si mesmo que se está abandonando a terra pátria, a casa e a sua própria vida até aquele momento. ${ }^{64}$ Contudo, no caso aqui exposto, com tantas peculiaridades, tais como as descritas anteriormente, a ideia do retorno para esses imigrantes japoneses residentes no Brasil teve um impacto ainda maior. Desde o início, viver no Brasil para retornar ao Japão foi um ideal a ser perseguido e poucas foram as iniciativas e mesmo a intenção de permanecer no Brasil. Em termos de representação identitária, tal situação os colocava permanentemente na condição de japoneses que viviam no Brasil, tão somente; tanto que, durante a guerra, a lealdade de suas identidades estava devotada ao Império Japonês.

Mas, assim como em todo processo migratório, que nunca é estanque ou unilateral, o período de residência no país de destino provoca múltiplas reflexões. Esse foi o caso quando, já em 1934, os japoneses decididos a permanecer no Brasil formaram o GAT Undo (de acordo com Maeyama, GAT é uma abreviação que significa "gozar a terra". O movimento defendia a residência em definitivo dos japoneses no Brasil, criando "um ambiente de descrédito e menosprezo à antiga ideia 'de regresso ao Japão', taxando-a de 'dekassegui konjo' (indigna disposição de trabalhador temporário)". ${ }^{65}$ Mesmo assim, podemos inferir que, ainda que entendendo o Brasil como um país de residência e não apenas de transição, o sentimento de ser um japonês no Brasil, em termos identitários, 
permanece. O desejo de viver no Brasil também se manifestou em associações, principalmente as formadas por descendentes de japoneses que nasceram no Brasil. Um exemplo é a Liga Estudantina Nipo-Brasileira, na qual descendentes de japoneses refletiam sobre sua identidade. Não apenas concluíram que eram brasileiros, como publicaram, em 1935, a revista Gakusei (Estudante) e, em 1939, a Transição. Nas publicações, escritas em português, reafirmavam sua brasilidade sem se esquecer da nacionalidade dos ancestrais. "Como poderemos amar a terra de nossos antepassados? Se nem a conhecemos? Podemos ter quando muito um sentimento de respeito pela pátria de nossos pais, mas nunca a ideia de patriotismo pela terra dos crisântemos" ${ }^{66}$ Aqui são percebidas as primeiras manifestações da identidade nacional atrelada ao Brasil, e não mais ao Japão.

Contudo, ainda que pequena parte da comunidade japonesa, notadamente os filhos que haviam nascido no Brasil ao longo das décadas de 1920, 1930 e 1940, já compreendesse que não eram japoneses e manifestassem algum amor ao território brasileiro como pátria e sentimento de pertencer a essa nação, a grande maioria dos imigrantes japoneses não partilhava dessa percepção. Somente após os episódios históricos relatados, inclusive os que envolveram a Shindo Renmei, é que a ideia do Brasil como pátria definitiva para si e especialmente para seus filhos e netos se coloca. Não havia como retornar para um Japão arrasado pela guerra. Não havia como voltar para um país que não existia mais.

Apesar de todas as confusões geradas com a derrota do Japão na Segunda Guerra Mundial, a maioria dos japoneses compreendeu a situação e se envergonhou com o desfecho dos acontecimentos, que puderam compreender com maior clareza após o restabelecimento das comunicações entre os dois países, avalia Maeyama. ${ }^{67}$ Nessa época, muitos japoneses se deram conta de que já estavam "profundamente enraizados ao solo brasileiro", deixando de lado o principal objetivo de suas vidas: retornar à terra natal. Os imigrantes entenderam que deveriam fixar-se

66 Cassio Kenro Shimomoto, "Nossa Mentalidade", Gakusei, ano 1, n. 1 (1935), apud Celia Sakurai, "Imigração tutelada: os japoneses no Brasil" (Tese de Doutorado, Universidade Estadual de Campinas, 2000), p. 162. 
definitivamente no Brasil, país onde nasceram e cresceram seus filhos e onde, em algumas das vezes, já haviam passado a maior parte de suas vidas. O Brasil, visto até então como uma casa hospedeira, onde estariam de passagem, passou a ser considerado país adotivo por parte dos colonos japoneses. No Japão, a relação de fidelidade dos filhos adotados para com o país adotivo é muito grande e a tradição japonesa diz que o filho adotado só deve retornar à sua terra de origem para visitar cordialmente, jamais deve voltar ao lar de origem. ${ }^{68}$

Um relato recolhido em pesquisa de campo por uma das autoras deste artigo é bastante elucidativo desse fato: Kazuhiro Mori, filho de japoneses, foi o primeiro herdeiro da família a nascer no Brasil. ${ }^{69}$ Aqui, formou-se médico e advogado. Aos 85 anos de idade (em 2015), ele relembrou, na entrevista, a conversa que teve com seu pai sobre o fim da guerra. A derrota japonesa representava, para sua família, assim como para a grande maioria das famílias japonesas que viviam no Brasil, o fim do sonho de retornar ao Japão. A pedido de Goiti Mori, o filho, então estudante do ginásio estadual em Araçatuba, voltou para casa, em Bilac, em um dia de semana para uma conversa.

Ele [Goiti Mori] disse "O Japão perdeu a guerra”. Eu [Kazuhiro Mori] disse: "não precisa falar, pra que isso? Lá [em Araçatuba] foi noticiado com rojão, com comício lá na praça, todos os estudantes do ginásio foram convocados para participar, para comemorar". Aí ele falou assim: "Nós não temos mais condições de voltar pro Japão e você é brasileiro. Sua missão agora é se tornar um bom brasileiro." E ele pra conversar isso teve que mandar eu voltar lá de Araçatuba pra passar uma noite lá [na casa, em Bilac]. No dia seguinte ele já tinha contratado um carro pra me levar de volta de manhã lá pelas 6h30. Eu já saí de carro de casa porque às $8 \mathrm{~h}$ começava a aula no ginásio estadual. ${ }^{70}$

68 Maeyama, "O antepassado", p. 444.

69 Danielle Yura, "Como explicar as associações ultranacionalistas japonesas no Brasil no pós Segunda Guerra Mundial? O caso Shindo Renmei” (Dissertação de Mestrado, Universidade Federal do ABC, 2016), pp. 189-194.

70 Yura, "Como explicar as associações ultranacionalistas japonesas no Brasil no pós Segunda Guerra Mundial? O caso Shindo Renmei” (Dissertação de Mestrado, Universidade Federal 
A notícia do pai, para o alívio de Kazuhiro, era que teriam de permanecer definitivamente no Brasil. O entrevistado afirma que não tinha vontade de viver no Japão, pois, além de ter seus amigos no Brasil, aqui estavam sua vida e seus estudos. "Lá, por conta da língua, teria que começar tudo de novo. E sei lá como a gente ia viver lá”, diz. Mais tarde, o pai e o tio de Kazuhiro, totalmente integrados à sociedade brasileira, foram assassinados pela Shindo Renmei por falarem abertamente sobre a derrota japonesa.

Em uma análise ideológica, Handa mostra que o sistema de ideias uniformizador japonês deixou de ser praticado pela maioria, passando, assim, a não ser mais alvo de preocupação entre os japoneses e descendentes. ${ }^{71} \mathrm{O}$ pensamento mais democrático não condenava sequer os nisseis (filhos de imigrantes japoneses) que não falassem a língua japonesa.

Muito embora o fluxo de imigração japonesa recebida pelo Brasil nunca mais tenha alcançado os mesmos índices do período pré-guerra, após o reestabelecimento das relações diplomáticas entre os dois países, a imigração Japão-Brasil se reconstitui. Esses novos imigrantes, contudo, assolados pelo terror da guerra que vivenciaram, não trazem a mesma perspectiva de transitoriedade no Brasil dos imigrantes que os antecederam. Como parte de suas decisões de partir já vislumbravam o Brasil como pátria adotiva e, não por acaso, seus filhos nascidos no Brasil, como regra geral, não possuem dupla cidadania e não dominam a língua japonesa. ${ }^{72}$

Observando todas essas tendências, conclui-se que a colônia do pós-guerra seguiu a mesma trajetória de democratização que se verificou tanto na sociedade brasileira como na japonesa. Sua assimilação ao Brasil se acentuou sobremaneira nessa época. Talvez possamos dizer que a modernização da colônia e sua assimilação à sociedade brasileira tenham ocorrido concomitantemente. ${ }^{73}$

do ABC, 2016), pp. 190-191.

71 Tomoo Handa, O imigrante japonês: história de sua vida no Brasil, São Paulo: T. A. Queiroz Editor, 1987.

72 Essa foi a realidade encontrada na pesquisa de campo de uma das autoras, durante os anos 1990, com imigrantes japoneses do pré e do pós-guerra.

73 Handa, O imigrante japonês, pp. 691-692. 
Essa integração pode ser notada em diferentes esferas, entre elas o número de casamentos interétnicos entre descendentes de japoneses e brasileiros ou descendentes de outras nacionalidades no Brasil. De acordo com o portal do governo paulista em comemoração ao centenário da imigração japonesa no Brasil, o isolamento étnico da colônia japonesa começou a se deteriorar na década de 1970, e a miscigenação passou a ser mais frequente na comunidade nipo-brasileira. ${ }^{74} \mathrm{Em} 2008$, $61 \%$ dos bisnetos de japoneses tinham alguma origem não nipônica. O portal aponta que os descendentes de terceira geração (chamados de sanseis) em diante que vivem no Brasil se integraram definitivamente à sociedade brasileira.

\section{E hoje?}

Como visto, o desfecho da Segunda Guerra Mundial trouxe, em termos do sentido de identidade para esses imigrantes japoneses e principalmente para seus filhos, a perspectiva de pertencimento à nação brasileira. Durante o período subsequente, especialmente as décadas de 1950, 1960 e 1970, a inserção desses imigrantes, seus filhos e netos na sociedade brasileira assume dimensões vertiginosas. O trabalho de Ruth Corrêa Leite Cardoso situa a transformação pela qual esse grupo passava nas décadas precedentes, após o término da guerra, amparado em estratégias familiares e comunitárias de mobilidade social. ${ }^{75}$ É fato que, no Brasil, os descendentes de japoneses foram alcançando, pouco a pouco, melhores posições sociais, desde as primeiras décadas da imigração. Mas a grande mobilidade social dessas pessoas deu-se no pós-guerra, quando a conscientização de permanência no Brasil, associada a outros fatores conjunturais - como o amparo associativo muito utilizado pelos imigrantes e a estrutura familiar estrategicamente planejada para a ascensão de todo o grupo, composta desde os tempos iniciais da imigração - foi favorecida pela própria conjuntura nacional de expansionismo econômico após a

74 “1908-2008: 100 anos: Imigração Japão-Brasil”, <http://www.saopaulo.sp.gov.br/imigracaojaponesa/historia.php>, acessado em 25/06/2016.

75 Ruth Corrêa Leite Cardoso, "Estrutura familiar e mobilidade social: estudo dos japoneses no estado de São Paulo" (Tese de Doutorado, Universidade de São Paulo, 1972). 
Segunda Guerra, que teve seu ponto culminante na década de 1970 com o "milagre econômico".76

Essa ascensão em termos econômicos refletiu-se em outros âmbitos, notadamente na melhor aceitação das características étnico-raciais que outrora tanto impacto causaram. O estudo de Jeffrey Lesser nos conduz a essa reflexão mediante a ideia de que os japoneses e seus descendentes "embranqueceram" para a sociedade brasileira à medida que foram ascendendo socialmente e ocupando cargos e profissões cada vez mais privilegiadas. ${ }^{77}$ "Ser japonês" nesse novo contexto de aceitação e inserção social na sociedade brasileira era muito distinto das condições absolutamente desfavoráveis vivenciadas no Brasil nas primeiras décadas de imigração. Entretanto, ainda que "embranquecidos" em termos econômicos e de aceitação social, não deixavam de ser "japoneses", especialmente para a sociedade brasileira, que assim os enxergava por carregarem os traços físicos de seus pais e avós.

A década de 1980 traz grandes modificações para a sociedade brasileira, a começar pelo período de transição dos vinte anos de ditadura militar para a tão esperada redemocratização do país. Em termos econômicos, entretanto, os anos 1980 nos legaram a triste nomenclatura de "década perdida", haja vista que os países da América Latina em geral não conseguiram desfrutar das mudanças estruturais que a economia impôs ao mundo naquele período. A partir do processo de redemocratização brasileiro, arduamente sonhado e almejado durante os anos de repressão, a devastadora crise econômica que assolou o país ao longo da década levou a uma frustração de parte da população, resultando em fenômenos migratórios diversos.

Após o choque vivenciado com a morte de Tancredo Neves, primeiro presidente civil que o Brasil teria tido desde 1964, a posse de Sarney, seu vice, com um governo que vigorou de 1985 a 1990, levou a economia brasileira a atingir inflação de $1.037,53 \%$ no ano de 1988 e $1.782,85 \%$ no ano de 1989 . Os planos econômicos sucessivos que tentavam domar a inflação galopante traduziam-se em tentativas de reor-

76 Cardoso, "Estrutura Familiar e Mobilidade Social".

77 Jeffrey Lesser, A negociação da identidade nacional: imigrantes, minorias e a luta pela etnicidade no Brasil, São Paulo: Editora Unesp, 2001. 
denamento ineficientes e demostraram a desordem econômica que foi vivenciada à época. Só no governo Sarney tivemos o Plano Cruzado (fevereiro de 1986); Plano Cruzado 2 (novembro de 1986); Plano Bresser (junho de 1987), Plano Verão (janeiro de 1989), com sucessivas trocas de moeda: Cruzeiro, Cruzado, Cruzado Novo. O golpe final seria dado em março de 1990, já no governo Collor - primeiro presidente eleito pelo voto direto desde 1960, quando aconteceu a eleição de Jânio Quadros -, com o confisco das poupanças realizado por meio do Plano de Estabilização Econômica, que ficou conhecido como Plano Collor (com a retomada da moeda Cruzeiro).$^{78}$ Este último atingiu em especial os segmentos médios da população brasileira e, não à toa, parte relevante e extremamente significativa de nossos fluxos de emigração.

Com a ascensão econômica vivenciada por grande parte das famílias de imigrantes japoneses e seus descendentes, esse grupo estava no centro dos processos emigratórios do Brasil. Mas não foi esse o único motivo de sua partida, pois nesse mesmo período a recuperação econômica do Japão explode, sendo a década de 1980 chamada de baburu keizai (bolha da economia). A recuperação do Japão pós-guerra impressiona e já nos anos 1980 o país estava entre as economias mais fortes do planeta e, possuindo uma população bem educada e que refutava trabalhos desqualificados (os famosos " 3 k": kitanai, kiken e kitsui - sujos, perigosos e pesados), viu como alternativa possível a entrada de imigrantes para ocupar tais postos. Dentre os que estavam dispostos a assumir esses trabalhos, os que descendiam de japoneses teriam prevalência nas entradas regularizadas. Assim concretizou-se uma das mais consolidadas correntes de emigração de brasileiros: a emigração de brasileiros descendentes de japoneses (ou a eles vinculados por laços matrimoniais) para o Japão, chamada migração dekassegui, ou decasségui, a depender da grafia adotada.

A imigração dekassegui possui inúmeras implicações: econômicas, jurídicas, sociais, antropológicas, históricas, demográficas. Interessa-nos, entre tantas possibilidades, a análise da percepção de identidade que esses migrantes vivenciam, que é bastante peculiar. Enquanto residentes no

78 Todas as contas correntes ou cadernetas de poupança que excedessem a NCz\$50mil (50 mil cruzados novos) foram congeladas por dezoito meses. 
Brasil, por mais que já tivessem sido aceitos pela sociedade e integrados a ela no que tange aos aspectos econômicos e sociais, ainda persistia uma noção de eram japoneses no Brasil. Essa percepção era partilhada tanto pelos próprios descendentes de japoneses quanto pela sociedade brasileira como um todo, que assim os caracterizava (e ainda os caracteriza) por seus traços físicos. Contudo, a vivência no Japão através do processo migratório "inverso" os coloca diante de situações contraditórias, pois os faz se perceberem estrangeiros na terra ancestral idealizada como sua. As possibilidades de ser um igual se desfazem rapidamente e a identidade à qual se vinculam, estando distantes do Brasil, é a do lugar que deixaram. Em outras palavras: "face a uma população fenotipicamente semelhante a eles, se percebem mais estrangeiros do que nunca". ${ }^{79}$

Hoje, passados mais de trinta anos de emigração dekassegui, muitos brasileiros residentes no Japão não tencionam mais voltar para o Brasil, assim como aconteceu outrora com seus antepassados. Outros tantos já retornaram e reconstruíram suas vidas aqui novamente, com a ajuda do capital adquirido em terras nipônicas. E outros, ainda, já retornaram para o Brasil e reemigraram mais uma vez para o Japão, ou mesmo para algum outro país, como Austrália ou Estados Unidos. Tantas são as histórias e tantas são as situações que podem ser vivenciadas por essa "brava gente brasileira". Mas são brasileiros? As identidades e condições de pertencimento, assim como tantas outras realidades, podem e são negociadas o tempo todo e se complexificam à medida que esses movimentos ocorrem. Inseridas em outro momento das condições internacionais de mobilidade do capital, a chamada globalização, as migrações de brasileiros rumo ao exterior contextualizam-se em um cenário de intensa mobilidade através do globo e forte dinamismo das condições de deslocamento. ${ }^{\mathbf{8 0}}$

O último surto de desenvolvimento tecnológico, vivenciado a partir da década de 1970 (a chamada Terceira Revolução Industrial), com a reestruturação do capital dentro dos modelos de acumulação flexível, propiciou um relativo barateamento dos transportes aéreos, acelerando as

79 Oliveira, "Japoneses no Brasil ou brasileiros no Japão", pp. 76-77.

80 Saskia Sassen, The Mobility of Labor and Capital: A Study in International Investment and Labor Flow, Cambridge: Cambridge University Press, 1988. 
condições de mobilidade entre as mais diversas partes do mundo ${ }^{81}$ Esse desenvolvimento também foi capaz de propiciar uma profunda revolução nas formas de comunicação tais quais as conhecíamos há vinte ou trinta anos, transformando completamente a questão do espaço-tempo. A comunicação instantânea através do espaço hoje não é mais exceção para poucos privilegiados, mas a cada dia se torna mais e mais acessível, inclusive para pessoas iletradas, que podem gravar suas mensagens via WhatsApp e com isso se comunicar com conhecidos ao redor do mundo. Migrar hoje não significa mais o que significou para nossos pais e avós - a partida definitiva para um destino implacável, a ausência de comunicação com quem ficou - muito embora ainda possa significar tudo isso também.

\section{Considerações finais}

O sentimento de pertencer, ter uma identidade, é historicamente construído e envolto em diversas variáveis objetivas e subjetivas. No mundo de hoje, esse "pertencer" tem se tornado cada vez mais "líquido", para parafrasearmos a noção de modernidade tão bem colocada por Bauman. ${ }^{\mathbf{2}}$ Essa fluidez das condições contemporâneas, presente no mundo do trabalho, nas questões do consumo e na volatilidade das relações, não está distante dos conflitos vivenciados pelos estados-nações e, consequentemente, das questões de pertencimento, identidade e nacionalidade. Assim como categorias antes consolidadas dentro de padrões muito mais rígidos, como a identidade de gênero e os papéis sociais, as identidades étnicas e o sentimento de pertencer a uma nação, tão característicos do século XIX e mesmo XX, tornam-se extremamente dinâmicos e passíveis de reflexão e contestação. Nesse contexto, os processos migratórios e as próprias fronteiras tornam-se difíceis de se vincularem a uma coisa só. Questões como o multiculturalismo e processos identitários, que são a proposta desse dossiê, se tornam emergentes e relevantes. Podemos observar cada vez menos os padrões encaixados na dinâmica do modelo ideal de es- 
tado-nação, território, cultura e povo, pois a intensidade das dinâmicas migratórias contemporâneas tem colocado em xeque esse paradigma.

É nesse contexto que podemos pensar a dinâmica extremamente rica e interessante da imigração japonesa para o Brasil e seu oposto, a emigração de brasileiros descendentes de japoneses para o Japão. As duas pontas do século XX são traçadas por esse processo: o início, com a chegada dos imigrantes japoneses, e as últimas décadas, com a ida de seus filhos e netos (e hoje bisnetos) para o Japão. As questões de identidade que permeiam essa relação são agudizadas em cada contexto vivenciado. Assim, o isolamento e as formas de marginalização sofridos pelos japoneses no início de sua imigração para o Brasil, resultado inclusive de percepções eugênicas sobre os critérios raciais almejados pela sociedade brasileira, acabam por permitir a leitura de uma realidade totalmente enviesada, na qual a censura da comunicação e de acesso a informações foi capaz de colocá-los diante de absurdos históricos e ressignificações impensáveis para os dias de hoje.

A intenção do governo brasileiro de dissuadir o isolamento dos imigrantes japoneses utilizando-se da repressão e de assimilá-los à identidade brasileira impositivamente age como um bumerangue, com efeito reverso: isolam-se ainda mais e fortalecem entre si o sentimento de serem japoneses. Anos mais tarde, o desqualificado "do ponto de vista antropo-estético" tornar-se-ia essencial para uma das nossas mais importantes correntes emigratórias, inclusive em termos de remessas para o Brasil (em termos de remessa, os brasileiros residentes no Japão são nossa segunda maior fonte de arrecadação através desse mecanismo). ${ }^{83}$ E, mais ainda, são eles essenciais na difusão e disseminação de costumes e características culturais essencialmente brasileiros do outro lado do mundo, ajudando a compor, inclusive, estratégias de nossa política externa na Ásia. Transportam essencialmente a nossa identidade para lá. Qual repressor poderia ter imaginado isso?

Recebido em 1/11/2017 e aprovado em 2/5/2018 


\section{Resumo}

Este artigo analisa os processos identitários vivenciados pelos imigrantes japoneses no Brasil no século XX, ressaltando o período de privações e discriminações enfrentadas por eles durante a Segunda Guerra Mundial. A marginalização dos japoneses acarretou a união desses imigrantes em torno de associações de caráter ultranacionalistas, como a Shindo Renmei. Essa conjuntura fortaleceu ainda mais o sentimento de ser um japonês que vive no Brasil, mas é um súdito fiel e leal às autoridades japonesas. Décadas mais tarde, quem perderia a guerra - dessa vez econômica - seria o Brasil, e os descendentes de japoneses viviam o fluxo inverso de seus pais e avós. Contudo, enquanto no Brasil são tratados como "japoneses", no Japão vivem a estranha experiência de serem brasileiros com "cara de japonês". $\mathrm{O}$ artigo está alicerçado em pesquisas teórico-empíricas das autoras que trazem à tona questões relevantes, como o impacto das restrições, censura na formação de identidades e o dinamismo do sentimento de pertencimento, que molda-se de acordo com o contexto histórico que o representa.

Palavras-chave: identidade - imigrantes japoneses - discriminação - Segunda Guerra Mundial - Shindo Renmei.

\section{Abstract}

This article analyzes the identity processes experienced by Japanese immigrants in Brazil throughout the $20^{\text {th }}$ century, highlighting the period of discrimination and censorship faced during World War II. Japanese isolation and marginalization during this period resulted in some of them uniting around ultranationalist associations, such as Shindo Renmei. This situation strengthened even more the feeling of being a Japanese living in Brazil, but faithful and loyal to the Japanese authorities. Decades later, Brazil would be the one to lose the war - this time economically - and the descendants of those Japanese immigrants embraced the reverse flow of their ancestors. However, while in Brazil they are treated as "Japanese", there they live the awkwardness of being Brazilians with "Japanese faces". This article is based on theoretical-empirical researches of the authors, bringing relevant issues such as the impact of restrictions and censorship on the formation of identities and the dynamism of the feeling of belonging, which is shaped according to the historical context that represents it.

Keywords: identity - Japanese immigrants - discrimination - World War II - Shindo Renmei. 